\title{
DEL VACÍO A LA RE-CREACIÓN: VIVENCIAS DE INFIDELIDAD Y RECUPERACIÓN
}

\section{From Emptiness to Re-Creation: Experiences of Infidelity and Recovery}

\author{
Maria Victoria Builes ${ }^{1}$, Alexandra María Ramírez ${ }^{2}$, \\ Beatriz Arango ${ }^{3}$, María Teresa Anderson ${ }^{4}$
}

https://doi.org/10.17533/udea.rp.e344350

\section{Resumen}

Objetivo: indagar acerca de las vivencias que tienen las parejas que se han recuperado luego de un evento de infidelidad. Método: el enfoque fue cualitativo y el método fue biográfico narrativo. Se realizaron entrevistas semiestructuradas con 8 parejas y uno de los miembros de otras 2, y un grupo de discusión con cuatro terapeutas. Resultados: las personas infidelizadas transitaron por las vivencias del vacío, de la falacia del control y de la vuelta en sí, para finalmente arribar de vuelta a la relación. Por su parte, las personas

\section{Abstract}

Objective: to inquire about the experiences of couples who have recovered after an event of infidelity. Method: the approach was qualitative, and the method was biographicalnarrative. Semi-structured interviews were

Recibido: 2020-11-04 / Aceptado: 2021-03-09

Para citar este artículo en APA: Builes, M. V., Ramírez, A. M., Arango, B. y Anderson, M. T. (2021). Del vacío a la re-creación: vivencias de infidelidad y recuperación. Revista de Psicología Universidad de Antioquia, 13(1), e344350. doi: https://doi.org/10.17533/udea.rp.e344350 infieles en su vivencia recorren el camino que va de ser 'pillados': la muerte simbólica tras el descubrimiento, al peso de la culpa y a la labor parresiástica, para culminar en la recreación de sí y de la relación. Conclusión: los participantes, además del dolor, se conocieron más a ellos y a sus parejas, y se re-crearon mediante la reflexión, para finalizar morando desde un lugar más estético su relación.

Palabras clave: pareja, infidelidad, vivencia, recuperación, creación.

conducted with 8 couples and one of the members of another 2 , and a discussion group with four therapists. Results: the infidelized people went through the experiences of emptiness, the fallacy of control and the
1 Médica, especialista en terapia familiar y magíster en educación y desarrollo humano. Profesora, Universidad de Antioquia, Colombia. Correo: maria.builes@udea.edu.co; http://orcid.org/0000-0002-7802-8615.

2 Médica y especialista en terapia familiar; https:// orcid.org/0000-0003-0679-1678.

3 Psicóloga y especialista en terapia familiar; https://orcid.org/0000-0003-3352-715.

4 Psicóloga y especialista en terapia familiar; https://orcid.org/0000-0001-5818-7195. 
return to itself, to finally arrive back to the relationship. For their part, unfaithful people in their experience travel the path that goes from being 'caught': symbolic death after the discovery, to the weight of guilt and parresiastic work, to culminate in the recreation of the 'self' and the relationship. Conclusion: the participants, in addition to the pain, got to know themselves and their partners more, and re-created themselves through reflection, to end up welling from a more aesthetic place, their relationship.

Keywords: couple, infidelity, experience, recovery, creation.

\section{Introducción}

La infidelidad ocurre en aproximadamente el $25 \%$ de los matrimonios y tiene consecuencias en la salud emocional y física, no solo para la pareja, sino también para los hijos (Coop y Mitchell, 2020; Thapa, Yang y Nget, 2019; Ventura, 2018; Knopp et al., 2017). En relación con el sexo y la infidelidad, Romero, Cruz y Rivera (2019) señalan cifras que varían entre el $8.5 \%$ y el $72 \%$ para las mujeres, y el $12 \%$ y el $82 \%$ entre los hombres, dependiendo de la cultura.

Para algunos autores (Fife, Weeksb y Stellberg, 2013), la infidelidad es una violación a un compromiso establecido en la pareja, referente a la intimidad sexual o emocional, o a ambas. La vivencia de cada miembro de la pareja es particular y va a estar ligada, entre otros factores, a su biografía, género, cultura, historia amorosa, creencias y significados en torno a la fidelidad (Alfonso y Hernández, 2020; Ángel, Rivera y Tonathiu, 2018; Masoumeh, Teo y Seyed, 2018). En la contemporaneidad, para algunas parejas el concepto de fidelidad se ha transformado, asumen nuevas formas de vinculación donde se permite el intercambio de pareja o ser una pareja abierta (Tobón, Vega y Cuervo, 2012).

Para el presente estudio, la infidelidad se concibió como la elección, de un sujeto de la pareja, de establecer relaciones afectivas o sexuales con una o varias personas, teniendo en cuenta que con la pareja inicial se tenía un acuerdo explícito o implícito de exclusividad afectiva y sexual (Eguiluz, 2007).

En los estudios (Abrahamson, Hussain, Khan y Schofield, 2012; Azhar, Abbas, Wenhong, Akhtar y Aqeel, 2018; Chi et al., 2019; Chu, 2020; Coop, Baucom y Sneyder, 2005; Jiménez, 2016; Molina, 2015; Parada, 2016. Scuka, 2015; Sodani, Abbasi, Mehr y Rajabi, 2019; Zumaya, Brown y Baker, 2008) 
se describe que la vivencia de la infidelidad, en ambos miembros de la pareja, está atravesada por sentimientos negativos como rabia, ira, profundo dolor, frustración, deseos de venganza, y por cambios en la autoestima, entre otros. En las personas cuya pareja ha sido infiel, las cuales de ahora en adelante nombraremos: personas infidelizadas, puede haber prácticas de hipervigilancia, sátira y rememoración. Por su parte, en las personas infieles pueden presentarse sentimientos de culpa o de negación tras el descubrimiento del acontecimiento. Cuando la infidelidad es realizada por una mujer, puede haber cuestionamiento de los valores, o bien puede ser interpretada como forma de resistencia femenina frente a las normas socialmente hegemónicas de representar a la mujer en cuanto madre o cuidadora, invisibilizando la dimensión del deseo (Yáñez y Rocha, 2015).

La vivencia de la infidelidad ha sido considerada un trauma (Coop et al., 2005; Fye y Mims, 2019; Heintzelman, Murdock, Krycak y Seay, 2014; Hall y Fincham, 2006; Khojastehmehr y Abbaspour, 2019; Leone, 2013; Scuka, 2015; Sodani, Gholammohammadi, Verdesoto, Villacís, y Franco, 2019) que pone en evidencia la fragilidad de lo humano y del fenómeno relacional, debido a que interroga la permanencia del vínculo. La palabra trauma

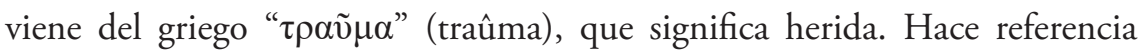
a la exposición a un acontecimiento abrumador e ineludible que supera la capacidad de afrontamiento del sujeto y suscita un daño que puede ser transitorio o permanente. El nivel del daño producido por el trauma estará en relación con el sistema de creencias, el apoyo psicosocial, los recursos internos y otras situaciones estresantes que se puedan estar viviendo en el momento o que se hayan vivido de manera recurrente (Cruz, 2012).

Para Stolorow (Hannush, 2008) el trauma produce una suerte de parálisis del tiempo, un congelamiento, una repetición del evento, lo cual afecta la manera de estar habitando la existencia presente, dado que en tanto trauma, hay una rememoración recurrente del evento de infidelidad.

La capacidad de integrar a la propia historia la irrupción que constituye la experiencia traumática está mediada por lo que Ricoeur $(2006,2003,1999)$ ha denominado trama, es decir, tejer narrativamente acontecimientos esperados e inesperados, darles un orden y atribuirles sentido, de tal manera que se pueda 
contar una historia. Para Ricoeur, lo anterior se denomina reconfiguración: la capacidad que tiene el sujeto de hilar, de integrar narrativamente los eventos no esperados, como en este caso la infidelidad. De este modo, el hecho de poder integrar el trauma como evento no esperado a la trama de la propia vida, suscita que el sujeto pueda "metamorfosear" la experiencia, representarla narrativamente, hacerla soportable y sobreponerse a ella (Cruz, 2012).

\section{Metodología}

El enfoque fue cualitativo, puesto que se indagó por la vivencia de las parejas que atravesaron una infidelidad y lograron mantener el vínculo. La investigación cualitativa (Rodríguez, Gil y García, 1996) se caracteriza por procurar aproximarse a la interpretación y comprensión de la realidad por parte de los sujetos desde un determinado objeto de estudio.

El método fue biográfico narrativo, en consideración de la propuesta de algunos autores (Figueiredo, 1999; Ricoeur, 1999; White, 2011) respecto a que la vida es un texto compuesto por diversos relatos, los cuales van dando sentido y norte al propio devenir. En esta investigación, la atribución de sentido a la experiencia biográfica de los participantes partió de relatos tantos individuales como de pareja.

Se llevaron a cabo 18 entrevistas semiestructuradas a 8 parejas y uno de los miembros de otras 2, las cuales fueron grabadas y transcritas, previo consentimiento. Para Kvale (2011), la entrevista semiestructurada es un espacio interactivo para la construcción de conocimiento; un diálogo a partir de preguntas sobre la experiencia y los significados atribuidos, donde los participantes dan cuenta de su vivencia íntima frente a un evento, en este caso: la infidelidad.

Más que categorizar o fragmentar, en cuanto se usó el método biográficonarrativo, se buscó dar cuenta de los relatos como un todo. La lectura organizada de las entrevistas permitió retomar los relatos que fueron haciendo posible captar la vivencia de los participantes, en función de la infidelidad. Los textos fueron seleccionados, organizados, y posteriormente articulados. Para efectos de triangulación, se llevó a cabo un grupo de discusión con 
cuatro terapeutas de la ciudad de Medellín que tenían amplia experiencia en el acompañamiento de este tipo de parejas. En el grupo se indagó acerca de la manera como las terapeutas abordaban el trabajo clínico con parejas que han vivido este tipo de situación, además se conversó sobre los aspectos que, en su experiencia, favorecen la recuperación luego de haber vivido una infidelidad. Estos últimos aspectos fueron muy importantes en las lecturas de los relatos del grupo, y fortalecieron y aportaron validez en el proceso de análisis de las parejas participantes.

\section{Participantes $^{1}$}

En la investigación participaron 18 personas pertenecientes a 10 parejas: 8 parejas completas y 2 miembros de otras 2 parejas. 9 de ellas fueron heterosexuales; 1, lésbica. Cinco de las parejas habían asistido a terapia por esta situación, y, por ende, las otras cinco no.

Se establecieron los siguientes criterios de inclusión: que las parejas al momento de la entrevista tuvieran como mínimo un 1 ańo de haber vivido el evento de la infidelidad, que permanecieran juntas y, desde su perspectiva, se hubieran recuperado de este evento.

Las edades de los participantes fluctuaron entre los 28 y 68 años. Todas las parejas vivían en unión libre o estaban casadas, y mínimamente convivían hace 4 años. Todas las personas firmaron el consentimiento informado avalado por el Comité de Ética de la Facultad de Medicina de la Universidad de Antioquia. Para mantener la confidencialidad, a lo largo de los relatos sus nombres serán modificados por nombres de diosas y dioses griegos.

\section{Resultados}

La vivencia de las parejas que experimentaron una infidelidad y luego reconocen que se recuperaron puede dividirse en lo que experimentaron las personas infidelizadas y lo que vivieron las infieles; a su vez, cada una de estas

Agradecemos a todas las mujeres y hombres que participaron del estudio y nos permitieron acceder a sus mundos privados. Así mismo, a la Universidad de Antioquia por alentarnos y apoyarnos en el deleite de investigar. 
vivencias tuvo dos momentos, a saber: el descubrimiento de la infidelidad y la recuperación.

\section{Vivencia de las personas infidelizadas}

\section{Descubrimiento de la infidelidad de la pareja}

Ellas y ellos refieren la experiencia como

... Fue el peor día de mi vida y no lo quiero volver a vivir nunca... Y a mi me dio muy duro no solamente lo que pasó, que obviamente es una bomba atómica en la vida de uno... una bomba atómica, donde explotó toda mi vida (Afrodita).

... Haz de cuenta como si a mi me hubiera entrado una bacteria, una cosa tenaz: escalofrios, sudaba de la nada; yo venía de estar bien y de eso cuando cerré el computador y supe todo, ya como de salud, la cosa más rara del mundo, temblaba, se me salian las lágrimas (Zeus).

Como que si te tragara un hueco, un agujero negro, y uno es como perdido. Qué hago... tú sientes que te metió en una piscina, te ahogó (Artemisa).

Estos participantes viven la infidelidad de su pareja desde lugares de profundo dolor; las analogías que utilizan lo evidencian. Adicionalmente, para estas personas esta vivencia se caracteriza por ser algo inesperado, cuyo impacto deja la sensación de destrucción, de caída en el vacío, sin saber en qué momento va a detenerse. Esta sensación deja el cuerpo colapsado, enferma, pero las implicaciones no son solo de esta índole, como se señaló, a nivel emocional se acompañó de dolor y de otras reacciones y sentimientos.

... Era como rabia, como decepción, como duda, desmotivación mil por ciento, y ya lo que se vino de aqui para delante fue una decepción profunda, un desamor muy grande... Bueno, y rabia y dolor (Zeus).

... Es un dolor, es una cosa que, uno por más que quiere, es muy dificil decir, es que no... Uno queda con su cosita en el corazón, con su maluquerita... Rabia, odio, ira, todo lo negativo que tú te imagines (Artemisa).

... Yo cogí la tarjeta de crédito y vi que él se habia ido para un motel, y eso fue una puñalada muy hijuemadre; yo no era capaz de hablar, era una cosa muy dura, no era capaz de llegar a la casa. Yo me puse a llorar, a llorar, hasta muy tarde por allá, para poder llegar a la casa. Yo le dije: "Nos vamos a separar" (Atenea). 
... Una rabia y como que mucho desprecio pues con él, no yo no consentía mirarlo (Deméter).

Así, a nivel emocional las sensaciones fluctúan entre el intenso dolor y la rabia. Son emociones negativas ocasionadas por la profunda decepción desencadenada tras descubrir el engańo de la pareja. La mezcla de dolores emocionales y físicos, representada en la analogía de la puńalada planteada por Atenea, lleva a estas personas a tomar decisiones iniciales como la separación.

A esta vivencia emocional y física le siguen vivencias cotidianas, descritas como

Yo me volvi una detective, pero sin sueldo y padeciendo eso, esa actitud detectivesca. Yo pensaba: Yo no puedo estar persiguiéndolo a todas partes. Yo digo que eso se fue calmando en mí, como lentamente yo fui otra vez, no tanto confiando, sino perdiendo el miedo a que él sea un hombre infiel, y entendi, que no entendía, que uno puede ser infiel y estar enamorado, pues y querer a su esposa. Como que para mi lo más valioso es que él me ame (Atenea).

... Si, yo tenía momentos en los que sentía que se perdia la confianza con esa situación y eso me hacía hacer lo que no quería hacer, que era mirar el teléfono. Si que durante un tiempo lo hice y después paré. Qué ridiculez pues; yo qué estoy haciendo... Y de verdad que se me volvió como una obsesión en un momento dado, y pienso que eso no tiene sentido, pues, yo ahi me equivoqué (Artemisa).

Cuando se realizan estas actividades de manera irreflexiva, pues muchas veces no se pueden controlar, las personas creen que van a poder purgar el dolor, que esta es la salida para controlar la ofensa y evitar que se repita. Sin embargo, conforme pasa el tiempo se van dando cuenta que es un trabajo desalentador, que no deja ningún tipo de satisfacción ni respiro, porque es imposible tener total control de todos los movimientos y llamadas de la pareja, es una creencia falaz. Además, vivir a la sombra de la pareja por el miedo a una nueva infidelidad hace que la propia vida se repliegue.

\section{Recuperación}

En esta etapa las personas infidelizadas van dejando atrás la falacia que impulsa el espionaje. La salida para estas participantes es de un orden mucho más profundo, está en el interior de ellas, en cuanto se deja de temer a la 
infidelidad. Cuando ellas aceptan lo impensable, a su vez asumen que no lo pueden controlar; se rinden. La vivencia adquiere un tinte de tranquilidad; primero, ellas encuentran que más que tener miedo hay que centrarse en ser amadas, $y$, en segundo término, en ver que la pareja hace sus esfuerzos y en ellas se dan nuevas formas de ser.

... Pero yo veo que él sí cambió, yo por eso fue que le perdoné a y él me dijo: “iMe va a dar otra oportunidad?", entonces, pues, yo al ver que llegaba temprano, que estaba muy pendiente otra vez de las cosas de la casa, de mí(Deméter).

... Siento que me fui tranquilizando, fui teniendo como la convicción que, de que las cosas podian cambiar, que él que era un hombre bueno, que mientras él no me faltara, que no se me perdiera, yo no tenía por qué estar también con esa obsesión tan pendeja (Hera).

... Verlo arrepentido a él, pedir perdón, yo creo que eso fue clave. Creo que hoy si él hubiera mentido, yo creo que para mi habría sido fatal, no hubiera dado posibilidades a una supervivencia (Atenea).

Ellas notan que sus parejas luego de equivocarse reconocen lo que hicieron, no sostienen la mentira, piden perdón por el daño ocasionado y buscan repararlas. Estos actos que sus parejas van llevando a cabo les ayudan a tranquilizarse y a confiar en que pueden sobreponerse luego de la hecatombe que supuso la infidelidad, y así mismo pueden, tanto ellas como sus parejas, volver a centrarse en la relación.

Esta respuesta de las parejas infieles enriquece una perspectiva que se descentra de aquella inicial solo referida al engaño. En la vivencia cotidiana se percibe que la pareja vuelve a otorgarle valor a la relación, que la recurrencia de la infidelidad eran cantos de sirena, en cuanto la idea de que esta podía volver a ocurrir y producir muerte simbólica, dado que la persona que conocían y en la cual confiaban podía engañar, siendo posible la ruptura del vínculo. En las narrativas analizadas, las personas infidelizadas vuelven a elegir a su pareja al recuperarse, aun sabiendo que se pueden equivocar, que son frágiles. Una posible explicación es que descubren que estas son más que infieles, y además de la fragilidad las habita también la potencia para reparar, para encarar, para amar. 
Otra de las vivencias dolorosas de la infidelidad es el cuestionamiento por la propia valía. El hecho de que la pareja mire en otra dirección socava el aprecio o admiración propia, golpea la "egoteca” (estantería, colección del ego).

Entonces a ti te aporrea el ego, te aporrean los valores, te aporrea lo que tú eres, tú no crees que seas capaz de hacer cosas. Te sientes por el piso, tu autoestima se baja. Empiezas a ser más temeroso (Afrodita).

... Me confrontaba mucho, yo sentía: A ver, es que yo soy tan poca cosa pues, que tan fácilmente él mira para otro lado y encuentra tan fácil. Sin embargo, yo fui entendiendo que entre él y yo habia una diferencia, yo no buscaba que me miraran y que me admiraran, aqui llegaba alguien y me decia algo y yo no lo alimentaba ni me interesaba alimentarlo (Hera).

En este último caso, la experiencia de dolor, mencionada en párrafos anteriores, se apacigua tras el paso de los días, en la medida que capta que el problema no radica en ella, en lo que tiene o en aquello de lo cual carece; realmente está en la necesidad de su pareja de ser apreciada, mirada y admirada. Esta situación es la que pone en riesgo la relación; como dirá Hera: «un jugar con fuego".

De esta manera, lograr diferenciarse de quien fue infiel, a partir de la restitución de la propia valía, ayuda a vivenciar el dolor de una forma más llevadera, no solo por la distancia que toma la persona infidelizada del acto de su pareja, sino también porque identificar la necesidad de ella implica conocerla y vivenciar desde un lugar más claro y sensato lo que se puede, o no, esperar de la relación. En esta vivencia reflexiva de la persona infidelizada hay una suerte de fortalecimiento de la propia estima y un reconocimiento de lo que se es y no se es.

La vivencia de los participantes infidelizados constituyó un proceso, en función de tiempos personales y relacionales que clasificamos de la siguiente manera:

- Caída libre: comprende la vivencia del dolor, la agitación, la decepción, la rabia que viene de la mano de todo evento no esperado y negativo, como fue para estas personas el evento de la infidelidad.

- La falacia del control: volverse Sherlock Holmes lleva a la persona infidelizada a vivir en el autoengańo del control, a vivir la vida de la otra 
persona, pensando que el seguimiento permanente de los movimientos y contactos que establece la pareja con los demás es el medio adecuado para procurar que no vuelvan a sufrir infidelidades y engaños; sin embargo, cuando son capaces, descubren que es una falacia.

- Vuelta en sí: es el tiempo de reflexión donde paulatinamente se vuelve a habitar la propia vida y se va reconfigurando el evento de la infidelidad, es decir, se va hilando el acontecimiento no esperado en la trama de la vida. En el caso de Hera, este proceso de trenzar, o de enredar y reconfigurar el evento, implicó diferenciarse de la pareja, reconociendo su fragilidad y necesidad de ser admirado, venerado, adulado, por personas externas a la relación. Al mismo tiempo, la persona infidelizada se ve a sí misma como un sujeto que tiene potencia y belleza, pero a su vez, fealdad y fragilidad, y que estas últimas, por sí mismas, no explican la infidelidad. En este tercer tránsito, la persona infidelizada comienza a soltarse del miedo, del dolor.

- Vuelta a la relación: luego de volver en sí comienza a ser posible mirar a la pareja con otra lente: ver su capacidad de desmarcarse de la infidelidad para compaginar nuevamente y morar estéticamente en el vínculo de pareja.

El corolario final es que la persona infidelizada no solo sufre profundamente, al final también aprende y sale fortalecida en su mismidad, en la relación y sabiendo más quién es ella y su pareja.

Básicamente es un aprendizaje, es como [que] soy más fuerte, pero soy más gente. Soy más fuerte como persona, no solo en la relación; o sea, la relación se fortalece porque tú creces, porque tú te vuelves como más conocedor de tus sentimientos y hasta donde puedes llegar. Como que entiendes más la visual del otro, por qué actúa de esa forma, para que no te impacte de forma tan negativa a ti (Artemisa).

\section{Vivencias de las personas infieles}

\section{Descubrimiento de la infidelidad}

La vivencia se asocia también con dolor, pero claramente desde otra perspectiva a la de sus parejas: 
... Pues me sentía mala, de verdad mala, de verdad, una persona mala, me sentía mala, muy... y pues, sentir una decepción de una persona que uno quiere como el papá o la mamá, pues, el esposo que te mire con esos ojos y te diga eso, no, pues uno se quiere tirar por un balcón. Yo creo que es de los peores sentimientos que uno puede tener. Era como no sé, una tristeza exagerada, era un arrepentimiento, una decepción de mí, creo que no... Eso es horrible, el peor 'mix' del universo (Hestia).

... Yo estaba destruida, sin vida. Yo me di cuenta, perderla a ella era como si... O sea, como que yo podía tener sentimientos hacia la otra chica, si, podría llegar y trabajar y decir: Listo, terminó mi relación, comienzo en otra relación o me meto en este bus de otra relación, pero sin ella, que es como el alma, es como el piso, como el todo; pero yo dije: No, ella es mi centro, eh, la amo por encima de muchas cosas. Fui a casa (Metis).

El dolor de la persona infiel se da por reconocer el propio mal, que se hizo mal, tras presenciar el dolor del otro al descubrir la infidelidad. Ver que el engaño sale a la luz deja en evidencia las consecuencias de esa experiencia que hasta ese momento era íntima. Entonces, la vivencia se carga de sentimientos como decepción y arrepentimiento, planteados con analogías como estar sin vida, quedarse sin alma, dando cuenta de una suerte de muerte simbólica, de desarraigo, dado que la pareja era el hogar, la familia. El descubrimiento de la infidelidad pone de frente la propia fragilidad y la posibilidad de perder la relación; esta doble evidencia se hace una carga dolorosa de llevar, porque elegir estar en otra relación (fragilidad) y ser descubierto produce una mezcla de sentimientos negativos que traen como posible consecuencia inicial la ruptura del vínculo.

De otro lado, solo uno de los participantes no requirió ser descubierto, su vivencia de dolor encapsulado lo lleva a contarle a su pareja lo que está pasando.

... Y se da un acercamiento, eso dura pues un tiempo y como resultado de eso esta persona queda en embarazo y tiene una niña que es mi hija, que vive con ella. Todo ese tiempo, pues, yo no dije nada, solo lo vine a decir cuando la niña tenía casi 2 años o 2 años largos, que digamos fue ya esa necesidad de expresar lo que habia sucedido. Eso fue muy dificil, muy duro. Yo no actué bien, y sentía que tenía que decir la verdad (Poseidón).

Este participante decide tramitar su dolor por la ruta de la verdad, no desea seguir engañando. Decir la verdad también fue doloroso, pero era lo correcto para él. 
La verdad, bien sea en cuanto revelación, o bien como descubrimiento, pone a estos participantes inicialmente en el lugar de la culpa por el mal cometido.

... A mi en algún momento me creó culpas, y no sanan a pesar de que en la terapia trabajé mucho y la terapeuta me enseñó mucho sobre la culpabilidad. No hay culpables, hay responsables. Pero quedan esos "pesos" (Hermes).

¿Por qué le hice daño a mi pareja, por qué? Entonces también era la confrontación conmigo, de ipara qué todo esto? Uno no mide estas consecuencias, por esto te digo que antes era como muy laxa, claro porque no me pillan... No sé cómo los narcos o no sé... Estoy muy bien porque nadie sabe que... que yo soy la que manejo, y yo estoy muy bien mientras tengo y muevo las fichas, pero cuando cae todo eso, pues obviamente soy ya vulnerada, todo el mal que he hecho (Hestia).

La experiencia de carga que genera la culpa da cuenta de que en ellos habita un sujeto moral, que puede reconocer y reflexionar sobre las elecciones que hizo; puede preguntarse por los sentidos que guiaron sus acciones, captar que antes existía una falacia del control sobre la situación que se quiebra cuando la verdad se hace evidente.

Pero hay un daño que ya está hecho independiente de eso, entonces mi lógica siempre... o fue en esa circunstancia: Yo no le estoy haciendo daño, me estoy haciendo daño a mí. Pero el daño se crea para todos los lados, para todos. La consecuencia de una situación de esta[s] es: fuego por todos los lados (Apolo).

Después yo me sentía, yo no me explicaba porque yo sentía el miedo a la sociedad. Claro, me van a señalar; casi la biblia: me van a apedrear, básicamente. Y yo decía: Debo perderme porque perdi al hombre más espectacular del mundo, iyo con esto no puedo! Pues, cómo decepciono, no solamente a mi esposo, sino a su familia, que cree en mí, que me quiere, a los amigos (Hestia).

Las consecuencias son de orden personal respecto al daño a sí mismo, al verse como una persona que miente, con una doble vida, que quedará marcada, señalada, dado que silencia lo que sabe que no está bien en términos de incumplir con el pacto explícito o implícito de fidelidad. Pero como todo acto personal, este tiene también efectos en el mundo relacional, en tanto daña a la pareja, la familia y al círculo de amistades. La metáfora «fuego por todos lados» alude a esos daños y el deseo de perderse evidencia una salida posible, después de reconocer el desastre. 
Hacer lo correcto, eso es un motivador en lo que yo hago y sé que aqui tuve una, incumpli a ese precepto, entonces digamos: desde esa época yo he dicho "voy a hacer lo correcto" y lo he hecho (Poseidón).

No niegan sus actos, los narran y vuelven a narrar; por voluntad propia, o por ser descubiertos, le hacen frente a la verdad.

... Nos fuimos con una botella de vino y se hablaron mil cosas, que de pronto, o por tranquilidad, o por esclarecimiento, o por crear un acercamiento, sirvieron. Yo creo que ese fue un momento de verdad liberador, nunca lo habia hablado con nadie. Fueron cosas que las vivi y dije: "Te lo estoy contando no para hacerte sentir mal, sino porque me quedé con eso, me lo tragué y aqui está el desastre (Apolo).

¡Pues ahi simplemente era decir la verdad! Ya pues que vamos a decir de otra cosa. Yo no sabia que él tenía esas pruebas, no sabia nada, pero, pues, para qué ya decirle que no, creo que habia que decirle la verdad (Hestia).

Decir la verdad, con o sin vino, ayuda a embriagar un poco el dolor y, además, contribuye a expresarlo, a envalentonarse para no mentir más; inclusive, esclarece y libera a la pareja, cuando saca a la luz lo que había permanecido oculto. En la vivencia de la narración, la persona que había sido excluida durante la infidelidad puede en ese momento ser incluida; esta experiencia, que implica dolor para ambos, va construyendo cercanía y, como dice Apolo, sirve para acercar a quien se tenía distanciado por el silencio, porque el desastre de la infidelidad también está en excluir, en no ver el rostro de la pareja.

Contar la verdad, por parte del infiel, también se analizó en el grupo de discusión como un elemento sanador:

... A través del diálogo que se construye, pues, en ese espacio terapéutico, se logra tratar de volver a construir como la confianza, ¿cierto? Y unos elementos que yo rescato ahi es que, en esa conversación en pro de construir esa confianza, por decirlo asi, el infiel empieza a hacerse cargo de lo ocurrido, y a través de hacerse cargo, entonces, pueden aparecer otros asuntos que tuvieron que ver con las problemáticas que llevaron a la infidelidad, entonces desarrollan una relación distinta.

La cura, en el relato del participante y de la terapeuta del grupo de discusión, emerge en tres ámbitos:

- El de la pareja, en cuanto ayuda en la reconstrucción de la confianza. 
- El subjetivo, por medio de hacerse responsable de los actos de infidelidad.

- El relacional, debido a que la conversación va abriendo otros horizontes que ayudan a arribar a un puerto más satisfactorio, a ser nuevamente cómplices y mantener el vínculo.

\section{Recuperación}

En este segundo momento se ha ido apagando el incendio - luego de reconocer que la infidelidad había sido fuego por todas partes—, se van viendo las cenizas, la oscuridad que trae consigo pasar por el fuego, ya no queda más que limpiar, recoger lo que se quemó y mirar si se puede recuperar algo, para volver a reconstruir.

... Él inmediatamente ese martes, al sábado, ya a las 2 de la tarde estaba en la casa, y en semana ya a las 7:30 de la noche estaba en la casa. Él ya el celular lo dejaba por a hi $y$ le cambió el genio, pues conmigo ya era más distinto, empezamos a salir a comernos un helado, a dialogar más (Deméter).

Esta acción está guiada por un propósito: recuperar a su familia. Saber cómo se puede perder esta lleva a la pareja de Hestia a buscar deshacer ese desenlace, por eso debe recordar lo acontecido y obrar exactamente de manera contraria.

Recuperarse y recuperar a la pareja no es un proceso que todo el tiempo va hacia adelante, en él también hay retrocesos:

... Y hemos venido pues ya 3 años largos de ires y venires, unos días mejores que otros, cada uno haciendo lo mejor que puede. Yo creo que ha sido una situación muy difícil, que no ha sido fácil (Poseidón).

No todo el tiempo es fácil, hay un ir y venir, lentitud, adversidad, pero también hay potencia, en la medida que se sabe que se está haciendo lo posible para aliviar y recuperar. La potencia es poder elegir qué hacer que acontezca.

... Hacer lo correcto, y lo he hecho, o desde el día en que lo dije y obviamente lo habia hecho antes también. Eso es como lo que yo sé, que es lo que me guia, es lo que hace que yo haga el esfuerzo, como jestoy aqui!', ¿cierto? Y eso lo aplico, pues, o hago hasta el mejor esfuerzo aplicable en todas las dimensiones de la vida (Poseidón). 
En este caso se sabe que hay que hacer que acontezca lo que es correcto para ellos. Lo humano no solo es falible, también es poiesis, en cuanto transformación, y re-creación.

El proceso por el que transitaron las personas que fueron infieles lo clasificamos en los siguientes momentos:

- Verse 'pillado': el descubrimiento produce una sensación de muerte; esta tiene dos fuentes: verse enfrentado al propio mal, en cuanto se ocasiona daño, y ver el dolor de la pareja. La muerte simbólica de este momento asfixia la prepotencia de pensar que no iba a pasar nada o que se tenía todo bajo control.

- El peso de la culpa: es la carga de volver sobre las propias acciones y elecciones, y descubrir que el placer obtenido no se compadece con el impacto negativo, o el fuego, que produce.

- La labor parresiástica: es poder contarle a la pareja lo que ocurrió. Narrar y volver a narrar permite ir reelaborando, como confesión del propio mal, los enredos que se fueron tejiendo para ser infiel, y, por medio de ese reconocimiento del mal, pasar de la culpa a la responsabilidad.

- La re-creación de sí y de la relación: implica elegir diferente, quedarse ahí con paciencia, persistencia, con nuevas formas para conversar y morar en la relación.

En este tránsito que fue personal y relacional, los sujetos infieles configuran nuevas formas de ser en esos ámbitos, que no borran las previas, las transforman.

\section{Lugares comunes entre infieles e infidelizados}

Estos son del ámbito del dolor y de la recuperación. La causa del sufrimiento obedece a razones diferentes, pero está atravesada por emociones negativas como rabia, culpa, fracaso, frustración y la falacia de control. El proceso para consolidar la recuperación culmina en el lugar de la vuelta en sí, para luego retornar estéticamente a la relación. Lo primero es muy importante 
para que emerja lo segundo: este trabajo de gestionar el propio dolor es lo que hace florecer a los miembros de la pareja, aliviar el miedo y curar esta emoción, y, tras ello, el dolor en la relación. Lo anterior se corrobora, en el grupo de discusión, como elemento terapéutico que se hace necesario en el acompańamiento a estas parejas:

Gestionar el propio dolor, porque yo creo que eso si es muy importante en el trabajo con la pareja; un poco ayudar como a que cada uno se encargue de lo que se tiene que encargar. Creo que una persona que vivió un episodio de infidelidad y le está doliendo mucho, si bien el otro puede hacer cosas para ayudar, que cada quien gestione su dolor es muy importante.

\section{Discusión}

Recapitulando, la vivencia de las personas que se recuperan de una infidelidad: infidelizado e infiel, luego de percatarse del evento, pasa por unos tiempos muy difíciles; para el infidelizado van desde la "caída al vacío", transitando por la falacia del control y la vuelta en sí, para terminar en la vuelta a la relación. Por su parte, para las personas infieles, su tránsito empieza con la 'pillada': la muerte simbólica del descubrimiento, navega hacia el peso de la culpa y luego a la labor parresiástica, para culminar en la re-creación de sí y de la relación. Estos resultados son novedosos en cuanto integran la vivencia de ambos miembros de la pareja, y, además, evidencian un proceso que va desde el dolor del descubrimiento hasta la recuperación, en formas que integran lo emocional, la praxis, lo personal y lo relacional.

Los hallazgos en torno a la vivencia inicial de dolor y la mezcla emocional se relacionan con lo encontrado en otros estudios (Abbasi et al., 2019; Ardalani, Refahi y Honarparvaran, 2016; Coop y Mitchell, 2020; Fincham y May, 2017; Hall y Fincham, 2006; Heintzelman et al., 2014; Leone, 2013; Knopp et al., 2017; Scuka, 2015; Shackelford, Buss y Bennett, 2002; Sodani, Abbasi et al., 2019), en los cuales la infidelidad es uno de los eventos más dolorosos para una pareja, asociándose con la experiencia traumática que deja importantes secuelas en los sujetos.

Por otra parte, el hecho de que las personas infidelizadas atraviesen por la falacia del control, es un concepto novedoso, puesto que la literatura 
usualmente enfatiza es la experiencia de desconfianza o de celos luego de una infidelidad (Calderón-Pérez, Flores-Galaz y Rivera-Aragón, 2018).

El hallazgo del peso de la culpa se relaciona, de un lado, con la perspectiva de Epicuro, para quien era una vivencia desorganizada de las pasiones, un desenfreno de los deseos (Lenis, 2016); de otro lado, con lo planteado por Ricoeur (Lenis, 2015), para quien la culpa es verse abrumado, justamente cargado por un peso; experiencia descrita por los participantes.

Respecto a la labor parresiástica de los infieles no se encontró referencia en los estudios revisados. Esta categoría se vincula con los planteamientos de Foucault (2012/2014;2001/2002) en sus últimos escritos. De otro lado, esta labor en los participantes del estudio, como en las escuelas helenísticas que ejercían la parresía, se evidencia a través de prácticas como el examen de conciencia, la confesión y la meditación (Borda, 2015). La actitud de los infieles transita a dejar de ocultar, contar y recontar; emerge como una forma de cura de sí y de la relación, por medio del restablecimiento del vínculo consigo mismo y con la pareja.

En las personas infidelizadas, la vivencia de la vuelta en sí implicó, entre otros aspectos, captar la propia belleza. Este hallazgo coincide con la investigación de Parada (2016), en la que se evidenció que el fortalecimiento de la autoestima es uno de los aspectos vividos en parejas que se recuperan de una infidelidad.

\section{Conclusiones}

La vivencia de las parejas que atraviesan por una infidelidad, y se recuperan, es un proceso que transita por diversos momentos, que van del mayor dolor a la reconfiguración de sí y de la relación. Esta vivencia implica unos tiempos personales y otros relacionales.

En los tiempos personales del proceso de recuperación de la infidelidad, la reflexión, el saber más de sí y de la pareja, mediados por decirse a sí mismo y al otro la verdad, son fundamentales para transitar de la caída en el vacío y la muerte simbólica, por el descubrimiento del evento, a la vuelta en sí y a la re-creación de sí y de la relación. Los miembros de la pareja no solo sufrieron, también se embellecieron y lograron embellecer más la relación, 
dado que conjuntamente el relato final fue aceptar el tránsito por el dolor sin negarlo, haciéndole frente, ensayando salidas y reflexionándolas, para después descubrir que el engaño o desear controlar a la pareja no conducían a un lugar tranquilo; captaron que era mejor el decir verdadero, soltarse del miedo y volver en sí, para terminar morando estéticamente en la relación.

Entre las limitaciones del estudio se encuentra el hecho de que no se contó con sujetos de diversas culturas del país y que solo participó una pareja lésbica, quedando por fuera la indagación de eventos de infidelidad en parejas gais o transexuales.

\section{Referencias}

Abrahamson, I., Hussain, R., Khan, A. y Schofield, M. J. (2012). What Helps Couples Rebuild Their Relationship After Infidelity? Journal of Family Issues, 33(11), 1494-1519. doi: https://dx.doi.org/10.1177/0192513X11424257

Alfonso, R. y Hernández, B. (2020). Significados del amor e historias de infidelidad en parejas que inician un proceso de psicoterapia. Diversitas: Perspectivas en Psicología, 16(1), 79-91. doi: https://dx.doi.org/10.15332/22563067.5542

Ángel, J., Rivera, S. y Tonathiu, P. (2018). La relación entre empatía e infidelidad. En R. Díaz, L. Reyes y López, F. (eds.), Aportaciones Actuales a la Psicología Social (vol. IV, pp. 1535-1550). Recuperado de https://www.investigacionyposgrado.uadec. $\mathrm{mx} / \mathrm{site} / \mathrm{wp}$-content/uploads/2020/04/Confiabilidad-y-validez-de-criterio-unaescala-de-desesperanza-para-adultos-mayores-mexicanos.pdf\#page $=55$

Ardalani, L., Refahi, Z. y Honarparvaran, N. (2016). Evaluate the Effectiveness of Training Imago-Therapy on Willingness to Forgive in Betrayed Couple. Indian Journal of Positive Psychology, 7(1), 88-92. Recuperado de https://www.questia. com/library/journal/1P3-4055684101/evaluate-the-effectiveness-of-trainingimago-therapy

Azhar, A., Abbas J., Wenhong, Z., Akhtar, T. y Aqeel. M. (2018). Linking Infidelity Stress, Anxiety and Depression: Evidence from Pakistan Married Couples and Divorced Individuals. International Journal of Human Rights in Healthcare, 11 (3), 214-228. doi: https://doi.org/10.1108/IJHRH-11-2017-0069

Borda, S. (2015). La reivindicación de la parresía en el último Foucault: algunas resonancias latinoamericanas y colombianas. Quaestiones Disputatae, 8(17), 136167. Recuperado de https://revistas.ustatunja.edu.co/index.php/qdisputatae/ article/view/988 
Calderón-Pérez, Y., Flores-Galaz, M. y Rivera-Aragón, S. (2018). Celos e infidelidad en personas heterosexuales y homosexuales: estudio intracultural. Acta de Investigación Psicológica, 8(1), 17. doi: https://dx.doi.org/10.22201/ fpsi.20074719e.2018.1.02

Chi, P., Tang, Y., Worthington, E., Chan, C., Lam. D. y Lin, X. (2019). Intrapersonal and Interpersonal Facilitators of Forgiveness Following Spousal Infidelity: A Stress and Coping Perspective. J. Clin. Psychol. 2019,75, 1896-1915. doi: https://doi.org/10.1002/jclp.22825

Chu, U. (2020). La infidelidad: acto de violencia (Tesis doctoral). Universidad César Vallejo, Chimbote, Perú.

Coop, K., Baucom, D. y Snyder, D. (2005). Treating Couples Recovering from Infidelity: An Integrative Approach. JCLP, 61(11), 1393-1405. doi: https:// dx.doi.org/10.1002/jclp.20189

Coop, K. y Mitchell, E. (2020). Infidelity in the Time of Covid 19. Fam Proc, 59, 956-966. Recuperado de http://text2fa.ir/wp-content/uploads/Text2fa.irInfidelity-in-the-Time-of-COVID-19.pdf

Cruz, L. (2012). Posibles deconstrucciones del trauma: Una aproximación posmoderna. Sociedad y Equidad, 3, 172-194. Recuperado de https://revistas. uchile.cl/index.php/RSE/article/view/18216/19340

Eguiluz, L. (2007). Entendiendo a la pareja. Marcos teóricos para el trabajo clínico. Pax: México.

Fife, S., Weeksb, G. y Stellberg, J. (2013). Facilitating Forgiveness in the Treatment of Infidelity: An Interpersonal Model. Journal of Family Therapy, 35, 343-367. doi: https://dx.doi.org/10.1111/j.1467-6427.2011.00561.x

Figueiredo, L. (1999). La filosofía narrativa de Alasdair MacIntyre. Navarra: Eunsa.

Fincham, F. y May, R. (2017). Infidelity in Romantic Relationships. Current Opinion in Psychology, 13, 70-74. doi: https://dx.doi.org/10.1016/j.copsyc.2016.03.008

Fye, M. y Mims, G. (2019). Preventing Infidelity: A Theory of Protective Factors. The Family Journal: Counseling and Therapy for Couples and Families, 27(1), 22-30. Recuperado de https://journals.sagepub.com/doi/ pdf/10.1177/1066480718809428

Foucault, M. (2001/2002). Hermenéutica del sujeto. Ciudad de México: Fondo de Cultura Económica.

Foucault, M. (2012/2014). Del gobierno de los vivos. Ciudad de México: Fondo de Cultura Económica. 
Hall, J. y Fincham, F. (2006). Relationship Dissolution Following Infidelity: The Roles of Attributions and Forgiveness. Journal of Social and Clinical Psychology, 25(5), 508-522.

Hannush, M. (2008). Trauma and Human Existence: Autobiographical, Psychoanalytic, and Philosophical Reflections. Journal of Phenomenological Psychology, 39, 213-253. doi: https://dx.doi.org/10.1163/156916208X311674

Heintzelman, A., Murdock, N. L., Krycak, R. C. y Seay, L. (2014). Recovery from Infidelity: Differentiation of Self, Trauma, Forgiveness, and Posttraumatic Growth Among Couples in Continuing Relationships. Couple and Family Psychology: Research and Practice, 3(1), 13-29. doi: https://dx.doi.org/10.1037/ cfp0000016

Jiménez, M. (2016). Transformación de significados con respecto a si mismo y a la experiencia de pareja de mujeres y hombres que han vivido historias de infidelidad (Tesis de maestría, Pontificia Universidad Javeriana). Recuperado de https://repository.javeriana.edu.co/bitstream/handle/10554/19054/ JimenezMolinaMaryAngelica2016.pdf?sequence $=1$

Knopp, K., Scott, S., Ritchie, L., Rhoades, G. K., Markman, H. J. y Stanley, S. M. (2017). Once a Cheater, always a Cheater? Serial Infidelity Across Subsequent Relationships. Archives of Sexual Behavior, 46(8), 2301-2311. doi: https://doi. org/10.1007/s10508-017-1018-1

Kvale, S. (2011). Las entrevistas en investigación cualitativa. Madrid: Morata.

Lenis, F. (2015). Avatares de la conciencia moral. Imputación, culpa y responsabilidad. Discusiones Filosóficas, 16(26), 69-85. doi: https://dx.doi.org/10.17151/ difil.2015.16.26.5

Lenis, F. (2016). Ética del placer. Culpa y felicidad en Epicuro. Praxis Filosófica, (42), 157-177. Recuperado de http://www.scielo.org.co/pdf/pafi/n42/n42a07.pdf

Leone, C. (2013). Helping Couples Heal from Infidelity: A Self Psychological, Intersubjective Approach. International Journal of Psychoanalytic Self Psychology, 8, 282-308.

Masoumeh, A., Teo, M. y Seyed, A. (2018). The Dark Triad of Personality and Infidelity Intentions: The Moderating Role of Relationship Experience. Personality and Individual Differences, 128, 49-54. Recuperado de https://www. sciencedirect.com/science/article/abs/pii/S0191886918300904?via\%3Dihub

Molina, D. (2015). Factores que contribuyen a que una experiencia de infidelidad tenga resultados positivos en una pareja: perspectivas de profesionales en el área de la salud 
mental que trabajan con parejas (Trabajo de grado, Universidad San Francisco de Quito). Recuperado de https://repositorio.usfq.edu.ec/handle/23000/4651

Parada, M. (2016). Recursos utilizados en la relación de pareja que ayudan a superar la crisis producida por la infidelidad (Tesis de maestría, Universidad de la Sabana). Recuperado de https://core.ac.uk/download/pdf/47068116.pdf

Ricoeur, P. (1999). Historia y narratividad. Barcelona: Paidós.

Ricoeur, P. (2003). Sí mismo como otro. Madrid: Siglo xxi.

Ricoeur, P. (2006). La vida: un relato en busca de narrador. Ágora, 25(25), 9-22.

Rodríguez, G., Gil, J. y García E. (1996). Metodología de la investigación cualitativa. Málaga: Aljibe.

Romero, A., Cruz, C. y Rivera, S. (2020). Propiedades psicométricas de la versión corta de la Escala de Conceptuación de la Infidelidad. Acta de investigación psicológica, 10(1), 91-100. doi: https://doi.org/10.22201/ fpsi.20074719e.2020.1.336

Scuka, R. (2015). A Clinician's Guide to Helping Couples Heal from the Trauma of Infidelity. Journal of Couple \& Relationship Therapy, 14, 141-168. doi: https:// dx.doi.org/10.1080/15332691.2014.953653

Shackelford, T., Buss, D. y Bennett, K. (2002). Forgiveness or Breakup: Sex Differences in Responses to a Partner's Infidelity. Cognition and Emotion, 16(2), 299-307.

Sodani, M., Abbasi, M., Mehr, R. K., y Rabaji, G. R. (2019). An Investigation into The Effect of Cognitive Existential Therapy on The Rumination of Women Affected by Male Infidelity NeuroQuantology, 17(5), 01-09. Recuperado de https://pdfs. semanticscholar.org/2e93/7461f357f65de9307a58b4934dc10e7c3e80.pdf

Sodani, M., Gholammohammadi, H., Khojastehmehr, R. y Abbaspour, Z. (2019). An Investigation into the Effectiveness of Robert Enright Forgiveness Inventory (EFI) on the Marital Quality of Women Affected by Infidelity. Biomedical Research, 30, (4). doi: 10.35841/biomedicalresearch.30-19-172

Thapa, R., Yang, Y. y Nget, M. (2019). Perceptions of Sexual Infidelity in Rural Cambodia: A Qualitative Study of Adolescent Men. American Journal of Men's Health, 13(3), 1557988319848576. doi: https://doi. org/10.1177/1557988319848576

Tobón, J., Vega, M. y Cuervo, J. (2012). Características de la construcción del vínculo afectivo de parejas en la juventud en la ciudad de Medellín. Revista CES Psicología, 5(1), 49-64. 
Ventura, D. (2018). Infidelidad en las relaciones de pareja: algunas consideraciones para su abordaje en terapia. Redes, 37, 61-72. Recuperado de http://www. redesdigital.com.mx/index.php/redes/article/view/240/6783426.

Verdesoto, J., Villacís, M. y Franco, X. (2019). Impacto emocional de la infidelidad en las relaciones de pareja. Importancia de su conocimiento para el psicólogo clínico. Opuntia Brava, 11(4), 349-361. Recuperado de http://200.14.53.83/ index.php/opuntiabrava/article/view/883.

White, M. (2011). Narrative Practice: Continuing the Conversations. New York: W.W. Norton \& Company.

Yáńez, K. y Rocha, T. (2015). Experiencias y significados de la infidelidad femenina. Psicología Iberoamericana, 22(2), 25-35.

Zumaya, M., Brown, C. y Baker, H. (2008). Las parejas y sus infidelidades. Revista de Investigación Médica Sur, 15(3), 225-230. Recuperado de https://www. medigraphic.com/pdfs/medsur/ms-2008/ms083i.pdf 